\title{
Comparison of segregations formed in unmodified and Sr-modified Al-Si alloys studied by atom probe tomography and transmission electron microscopy
}

Jenifer Barrirero, Michael Engstler, Naureen Ghafoor, Niels de Jonge, Magnus Odén and Frank Muecklich

\author{
Linköping University Post Print
}

\section{Tweet}

N.B.: When citing this work, cite the original article.

Original Publication:

Jenifer Barrirero, Michael Engstler, Naureen Ghafoor, Niels de Jonge, Magnus Odén and Frank Muecklich, Comparison of segregations formed in unmodified and Sr-modified Al-Si alloys studied by atom probe tomography and transmission electron microscopy, 2014, Journal of Alloys and Compounds, (611), 410-421.

http://dx.doi.org/10.1016/j.jallcom.2014.05.121

Copyright: Elsevier

http://www.elsevier.com/

Postprint available at: Linköping University Electronic Press http://urn.kb.se/resolve?urn=urn:nbn:se:liu:diva-109356 


\title{
Comparison of segregations formed in unmodified and Sr-modified Al-Si alloys studied by atom probe tomography and transmission electron microscopy
}

Jenifer Barrirero ${ }^{a, b}$, Michael Engstler ${ }^{a}$, Naureen Ghafoor $^{b}$, Niels de Jonge ${ }^{c}$, Magnus Odén ${ }^{b}$, Frank Mücklich ${ }^{a}$

\author{
${ }^{a}$ Chair of Functional Materials, Department of Materials Science, Campus D3 3, Saarland \\ University, D-66123 Saarbrücken, Germany \\ ${ }^{b}$ Nanostructured Materials, Department of Physics, Chemistry and Biology, Linköping \\ University, SE-581 83 Linköping, Sweden \\ ${ }^{\mathrm{c}}$ Innovative Electron Microscopy, INM-Leibniz Institute for New Materials, Campus D2 2, \\ Saarland University, D-66123 Saarbrücken, Germany
}

\begin{abstract}
The mechanical properties of Al-7 wt.\% Si can be enhanced by structural modifications of its eutectic phase. Addition of low concentrations of certain elements, in this case $150 \mathrm{wt}-\mathrm{ppm}$ $\mathrm{Sr}$, is enough to cause a transition from a coarse plate-like Si structure to a finer coralline one. To fully understand the operating mechanism of this modification, the composition of the eutectic Si phase in unmodified and Sr-modified alloys was analysed and compared by Atom Probe Tomography and (Scanning) Transmission Electron Microscopy. The unmodified alloy showed nanometre sized Al-segregations decorating defects, while the Sr-modified sample presented three types of Al-Sr segregations: (1) rod-like segregations that promote smoothening of the Al-Si boundaries in the eutectic phase, (2) particle-like segregations comparable to the ones seen in the unmodified alloy, and (3) planar segregations favouring the formation of twin boundaries. Al and Sr solubilities in Si after solidification were determined to be $430 \pm 160$ at-ppm and $40 \pm 10$ at-ppm, respectively. Sr predominantly segregates to the Si phase confirming its importance in the modification of the eutectic growth.
\end{abstract}


Keywords: aluminium-silicon alloys; strontium modification; atom probe tomography; transmission electron microscopy; microstructure

\section{Introduction}

Al-Si are the most widely used aluminium casting alloys on account of their superior castability properties, e.g. high fluidity, low shrinkage and low thermal expansion coefficient. In this study, the hypoeutectic alloy with $7 \mathrm{wt} . \% \mathrm{Si}$, composed of $\alpha-\mathrm{Al}$ dendrites and Al-Si eutectic phase will be considered. The microstructure of the irregular eutectic phase is formed by coarse Si plates embedded in an aluminium matrix. The brittle Si plates embedded in the ductile Al matrix act as internal stress raisers and provide easy paths for cracks. By the addition of low concentrations of certain elements such as strontium (50 - 400 wt-ppm Sr), the microstructure of the Si phase can be modified to a coralline-like structure. In the presence of such a modifier the structure becomes finer and the brittle Si phase more rounded, contributing to higher values of ultimate tensile strength, greatly increased ductility, improved impact properties and better resistance to thermal shock [1].

These attractive properties have led to a wide industrial use of modified AlSi-based alloys in, for example, engine parts in the automotive industry. However, it remains difficult to optimize the amount of the modifier in terms of formation of intermetallic phases and homogeneity of the modification, especially for large-scale casts of complex alloys such as AISiMg that often also contain impurities such as Fe and P. Fundamental understanding of the mechanisms governing the microstructural modification is still lacking, including how different species interact and affect the microstructure.

$\mathrm{Na}$ and Sr modifications of AISi alloys have been extensively studied and numerous theories are proposed to explain the underlying phenomena [2-12]. In general, two approaches to explain the structural modification can be distinguished: the influence of the modifier on nucleation [13-16] and at the growth front of the eutectic phase [2-8,10]. The most well accepted hypotheses dealing with eutectic growth claim a Si growth restriction through the 
accumulation and adsorption of the modifier at the solid-liquid front. Lu and Hellawell [10] for instance, presented the impurity induced twinning (IIT) theory, through which step sources across the $\{111\}$ closely packed planes in Si would be poisoned by the modifier, promoting frequent twinning. Similarly, other authors based their explanations on a mechanism, which is believed to be operative at the modified and unmodified eutectic: the twin plane re-entrant edge (TPRE) mechanism [2,7]. This mechanism suggests that the presence of twins forms re-entrant edges that facilitate Si growth in the $<211>$ direction [7]. In this case, the proposal is that the modifier will poison these re-entrant $\{111\}$ twin grooves. Although based on different growth modes, both of these approaches relay on the hypothesis of a high multiplication of twins. Even if the morphology of eutectic Si appears to be almost isotropic, the underlying mechanism is believed to be an anisotropic growth with several changes of growth direction. Shamsuzzoha and Hogan [8] used this idea to propose a zigzag type of growth induced by the repeated twinning of the Si crystal during growth.

To confirm or reject the Si-growth mechanisms proposed by these theories, a more detailed investigation of the distribution of the modifier in the Si-phase, its tendency to segregate and its correlation with twins and other structural defects is needed. This verification, however, was hindered during the last decades by the lack of spatially resolved chemical information at the nanometric scale. With the advent and development of high resolution transmission electron microscopy (HR-TEM), atomically resolved scanning transmission electron microscopy (STEM) and atom probe tomography (APT), high structural and 3D chemical resolution down to parts per million [17] is now attainable. Recent studies of Sr modified samples showed evidences of segregation of the modifier together with Al inside the Si phase [18-20]. The presence of Al was not expected or predicted by any of the previously mentioned theories of modification and it remains difficult to ascertain if its presence plays a decisive role. One important missing piece to the understanding of the modified structure is a detailed characterization of the Si phase in the unmodified alloy, i.e. without Sr. The comparison of the overall Al concentration and distribution between modified and unmodified samples will help in the interpretation of its role for the modification. In addition, the 
measurement of the overall Sr concentration in the Si phase will give information about the necessary amount of Sr to achieve modification.

In this study, chemical and structural information about the concentration and distribution of $\mathrm{Al}$ and $\mathrm{Sr}$ in the unmodified and Sr-modified eutectic Si were obtained by means of APT, TEM and STEM. The segregations detected using APT combined with the structural features imaged by (S)TEM give a detailed three-dimensional view of the Si phase, which allowed us to trace the microstructural evolution of these alloys.

\section{Materials and Methods}

Al-7 wt\% Si (AISi7) samples were produced at the Foundry Institute at RWTH Aachen by directional solidification in a Bridgman furnace. All samples were fabricated with a cooling rate of $0.25 \mathrm{~K} / \mathrm{s}$ at a temperature gradient of $15 \mathrm{~K} / \mathrm{mm}$. High purity Si and Al (Al5N5) were melted at the corresponding proportions. An aluminium master alloy containing $15 \mathrm{wt} . \% \mathrm{Sr}$ was added to modify the samples with 150 wt-ppm Sr. Chemical compositions were determined by optical emission spectrometry and are presented in Table I.

Cross-sectional cuts of the samples were embedded and mechanically polished. Site-specific sample preparation for TEM and APT were accomplished in a dual-beam focused ion beam / scanning electron microscopy workstation (FIB/SEM) (Helios NanoLab 600 ${ }^{\mathrm{TM}}$, FEI Company, USA). In both procedures, an electron beam induced Pt-cap layer was first deposited on the eutectic area to provide protection from gallium implantation. After lift out and thinning of the samples, a low energy milling at $2 \mathrm{kV}$ was performed to minimize $\mathrm{Ga}$ induced damage [21]. Electron back scattered diffraction (EBSD) was accomplished using an EDAX Hikari EBSD system attached to the FIB/SEM-instrument on the modified sample to assess the twin density in the Si phase. The sample polishing procedure for EBSD-measurements using colloidal silica as polishing media was optimized to get the best data quality from the Siphase. The raw data corresponding to the Al phase was filtered out from the EBSD maps for clarity. 
Overview and HR-TEM images were recorded in a Tecnai G2 TF 20 UT FEG microscope (FEI Company, USA) operated at $200 \mathrm{kV}$ in micro and nanoprobe mode. STEM images were acquired using an ARM 200 microscope (JEOL, Japan) also operated at 200kV and equipped with a corrector for spherical aberration (CEOS, Germany). The corrector was aligned for a sub-Ångstrom probe size. A beam shower procedure was applied to reduce the amount of contamination during high-resolution imaging using a high angle annular dark field (HAADF) detector. To enhance the contrast, the atom-resolved HAADF-STEM images were filtered by the image processing software Fiji [22]. The images were transformed into the frequency space by a Fast Fourier Transform (FFT). All frequencies except for the central one were individually encircled and passed through a white mask. Finally, the masked information was transformed back to the space domain by an Inverse-FFT. Laser Pulsed APT was carried out with a LEAP TM 3000X HR (CAMECA) at a repetition rate of $250 \mathrm{kHz}$, a specimen temperature of about $40 \mathrm{~K}$, a pressure lower than $1 \times 10^{-10}$ Torr (1.33 $x 10^{-8} \mathrm{~Pa}$ ), and a laser pulse energy of $0.4-0.5 \mathrm{~nJ}$. The evaporation rate of the specimen was 5 atoms per 1000 pulses. Datasets were then reconstructed and analysed with the IVAS ${ }^{\mathrm{TM}}$ 3.6.6 software (CAMECA). Reconstructions were calibrated by comparison with SEM images post measurement and the use of crystallographic features within the reconstruction. Localized chemical analysis was carried out using one dimensional concentration profiles and proximity histograms. The sampling of the concentration profile measurements was adjusted to minimize statistical errors using fixed number of ions per sampling block. Proximity histograms were constructed based on Al iso-concentration surfaces. Isoconcentration surfaces are shown in some figures to highlight the presence of segregations and their morphologies. The Al and Sr contents in Si and their solid solubilities were measured after background subtraction in IVAS software.

\section{Results}

Figure 1 shows typical optical micrographs of the analysed AlSi7 samples. The unmodified plate-like eutectic Si phase presents a much coarser structure in comparison to the Sr- 
modified eutectic. Although Figure 1(b) depicts small rounded disconnected particles in the transversal section, the three-dimensional structure consists of an interconnected corallinelike architecture [23].

The distribution and concentrations of $\mathrm{Al}$ and $\mathrm{Sr}$ in Si were analysed by APT and (S)TEM for both alloys. The different types of segregations found are summarized in Table II. Detailed descriptions of the microstructural findings for the two alloys are presented separately in the following sections.

\subsection{Unmodified alloy - AlSi7}

Figure 2 shows a transversal cut of a Si plate. The presence of twins along the plate confirms the expected twin plane re-entrant edge (TPRE) growth of eutectic Si $[2,7,24]$. The magnified area shown in figure 2(b) evidences not only twins, but also an unexpected homogeneous distribution of round precipitates. HR-TEM of these precipitates showed that they are coherent with the crystalline matrix (figure 2(c)). The particle's diameters measured by HRTEM ranged between 10 and $12 \mathrm{~nm}$.

For compositional insight, six eutectic Si atom probe specimens were analysed. All specimens contained Al segregations in agreement with the precipitates imaged by TEM. Figure 3 shows one of such measurements giving a representative view of the density of segregations. A total of 16 such features were analysed separately using one dimensional concentration profiles and proximity histograms in order to categorize the segregations. Based on the results, the segregations were divided into three categories as seen in figure 3 $(b, c, d)$ :

1. Small segregations with a diameter between 5 and $10 \mathrm{~nm}$ and a homogeneous $\mathrm{Al}$ concentration in the range of 5 to 15 at.\% Al (figure 3 (b)). Three of such segregations were analysed.

2. Larger segregations with a diameter between 13 and $18 \mathrm{~nm}$. These features showed markedly uneven concentration profiles as the one depicted in figure 3(c) with a low Al concentration in the centre and a higher concentration at the surroundings 
between 40 and 50 at.\% Al. 12 segregations with such an Al depleted zone in the centre were measured.

3. Ring-like segregation with a diameter of $40 \mathrm{~nm}$ and a peak concentration of 6 at.\% Al. Only one of these segregations was detected (figure 3(d)).

The measurement of Al segregations in a Si matrix by APT is a challenging task. Al evaporates at lower field strengths than Si [25] and this fact influences the accuracy of the atoms' positions in the reconstructed volume [26]. Deflections of the ion trajectories affect primarily particle-like segregations since the uneven distribution of the electric field at the specimen surface is strongly localized in this case. This local magnification artefact results in a deformation of the segregation in the $x-y$ direction [27]. Lefevbre et al [28] reported a 1.5 to $2 \mathrm{~nm}$ region affected by trajectory overlaps at the interface of low-evaporation-field precipitates. Considering this biased area, we expect the significant Al depletion detected at the centre of the large segregations (13-18 nm diameter) not to be an artefact from trajectory aberrations. However, the compositional measurements along the segregation interface, for example as shown in Fig. 3 (c), can present up to \pm 5 at. $\%$ error.

\subsection{Modified alloy - AlSi7 + 150 wt-ppm Sr}

Figure 4 shows overviews of the modified eutectic structure at two different magnifications. Figure 4(a) shows an inverse pole figure as obtained by electron back scattered diffraction (EBSD). This map was obtained at a surface perpendicular to the solidification axis similar to the one shown in figure $1(\mathrm{~b})$ and only shows the Si phase. This EBSD map shows the crystallographic orientations in the Si phase. The majority of the Si branches present two crystallographic orientations separated by a twin boundary highlighted in black in the figure. Figure 4(b,c) display TEM overview images of surfaces perpendicular to the EBSD map. Both of these images also show two Si crystallographic orientations separated by a twin boundary. A clear difference between the twin boundaries seen in the unmodified (Fig. 2) 
and in the modified alloy is that, in the modified case there is no unique twin plane. Instead, the twin boundary displays several different directions indicating repeated changes of the growth front direction during solidification, i.e. the modified alloy is characterised with a higher degree of growth flexibility compared to the unmodified alloy.

In addition to these coarse changes of growth direction, the modified alloy presents a high density of nanometre sized features embedded in the single-crystalline Si lattice. These features include precipitates as found in the unmodified alloy, twins involving just a few tens of crystallographic planes, and faults in the Si stacking sequence involving a few inter-planar distances. These features were analysed by (S)TEM and correlated to AI-Sr segregations measured by APT. No segregations presenting Al or Sr alone were detected. Depending on their morphology, the segregations were categorized into three types: rod-like, particle-like and planar.

\section{a. Rod-like segregations}

Rod-like segregations are here defined as segregations having one dimension significantly larger than the other two. Figure 5 shows a complete APT reconstruction of a Si specimen where rod-like segregations containing $\mathrm{Al}$ and $\mathrm{Sr}$ are the dominating features (see supplementary data Video 1 for a full three-dimensional view). Figure 5(a) shows a top- and lateral-view of an $8 \mathrm{~nm}$ thick slice through the measurement. This slice presents numerous rod-like segregations rich in $\mathrm{Al}$ and $\mathrm{Sr}$. In the upper part of the reconstruction, a V-shaped arrangement with a precipitate at its intersection is seen; while at the lower part, several parallel segregations separated by 10 to $30 \mathrm{~nm}$ are shown. Figure 5(b) shows the top- and lateral-view of a $90^{\circ}$ rotation of this reconstruction. This image shows further segregations branching out and illustrates the three-dimensional complexity of the phase. Top- and lateral magnifications of these segregations are displayed in figure 5(c) with $\mathrm{Al}$ and $\mathrm{Sr}$ atoms represented as spheres. These segregations are separated by 5 to $10 \mathrm{~nm}$. Rod-like segregations were always longer than the field of view of the tomographies. The maximal lengths that could be measured by APT were about $200 \mathrm{~nm}$. 
Concentration profiles obtained along these segregations showed between 2 - 4 at.\% $\mathrm{Al}$ and 0.5 - 1 at.\% Sr. Fig. 5 (d) depicts one example of such concentration profile calculated in a cylindrical region of interest (ROI). The diameter size has a critical influence on the concentration measured, and therefore, it was chosen as close as possible to the segregation with a diameter of $3 \mathrm{~nm}$. Since the background noise signal cannot be identified in the 3D space data, it cannot be subtracted from the concentration profiles. To evaluate the background level, we extracted the mass spectrum data inside the selected ROI. This mass spectrum data shows $0.87 \pm 0.09$ at. $\% \mathrm{Sr}$ and $3.16 \pm 0.17$ at. $\% \mathrm{Al}$ in agreement with the profile measurement and indicating a minor influence of the background. Concentrations measured in such small regions in the reconstructions should be treated carefully due to the limited detection efficiency of the instrument [29]. As a consequence, we report Al:Sr ratio rather than concentrations. Here, all rod-like segregations present between 2.5 and 4 times more Al than Sr, which is what to expect if local ternary reactions have formed intermetallic phases.

Figure 6(a) shows a dark field TEM image of a Si branch containing a high amount of Vshaped defects. These features start in the inner part of the Si branch and extend towards the Al-Si boundary. Figure 6 (b) illustrates the correlation with the Al-Sr segregations presented in figure 5 by APT. These features were frequently found in the samples. Figure 7(a) shows an APT region of interest containing V-shaped Al-Sr segregations with spheroidal segregations heterogeneously nucleating along them and at their intersections. Figure $7(b)$ is a HRTEM image viewed along the $<011>$ zone axis of the Si crystal displaying V-shaped defects along two $<111>$ directions at an angle of $70.5^{\circ}$. This defect consists of faults in the stacking sequence involving a few lattice planes. We note that this is not a twin type defect since the Si lattice orientation is the same on both sides of the defect. This is further confirmed by the atomically resolved HAADF-STEM image in figure 7 (c). The atomic structure aligned in the $<110>$ zone axis depicts the Si arrangement into the characteristic dumbbells of the diamond structure. The Si structure is maintained at both sides of the segregation and the distortion of the crystal structure corresponds to three lattice planes. 


\section{b. Particle-like segregations}

Particle-like segregations containing $\mathrm{Al}$ and $\mathrm{Sr}$ were found in all APT reconstructions and

(S)TEM images. Similarly as in the unmodified alloy, two size-ranges of particle-like segregations are present:

1. Segregations smaller than $10 \mathrm{~nm}$. These features can be seen in figure $5(\mathrm{~b})$. The difference to the unmodified sample is not only the presence of Sr together with $\mathrm{Al}$, but also a very high density of these segregations only in one part of the specimen. Figure 5(b) shows a dotted line highlighting the "virtual plane" behind which the segregations are accumulated.

2. Larger segregations (>10 nm). Several of these segregations are presented in the APT reconstruction of figure 8(a). Figure 8(c) shows a magnification of one of them. Al and Sr present similar fluctuations in concentration as in the unmodified sample with an Al-depleted zone in the centre of the feature.

The $\mathrm{Al}$ and $\mathrm{Sr}$ concentrations in the segregations vary and ranges from 7 to 20 at.\% $\mathrm{Al}$ and 0.2 to 0.8 at.\% Sr. In some precipitates there is up to 30 times more Al than Sr.

\section{c. Planar segregations}

Planar segregations are the third type of features found by APT measurements. They are described by having two dimensions significantly larger than the third one. Due to their large size a definite correlation to the TEM images is not straightforward for this type of segregations. However, they are probably situated at grain boundaries and irregular twin boundaries as the one presented in figure 4.

Figure $8(\mathrm{~b})$ shows one example of a planar segregation that is $1 \mathrm{~nm}$ thick (see supplementary data Video 2 for a full three-dimensional view). The segregation crosses the entire atom probe specimen, which has a diameter of approximately $70 \mathrm{~nm}$. The size of this segregation is larger than the field of view and can therefore not be estimated. The Al and $\mathrm{Sr}$ distributions are constant such that an $\mathrm{Al}$ :Sr ratio of about 2.5 is maintained throughout the 
segregation with peak contents of 5 at.\% Sr and 12 at.\% Al at the segregation centre. We note that the $\mathrm{Al}: \mathrm{Sr}$ ratio is comparable to that measured for the rod-like segregations.

\subsection{Al and $\mathrm{Sr}$ concentrations in $\mathrm{Si}$}

The data of 7 specimens of the modified and 6 specimens of the unmodified alloy were averaged to obtain the $\mathrm{Al}$ and Sr concentrations in the Si-phase of each alloy.

The amount of Al and Sr in solid solution in each alloy are reported in Table III and are $430 \pm$ 160 at-ppm for $\mathrm{Al}$ and $40 \pm 10$ at-ppm for Sr. These values represent a measure of the solubility of $\mathrm{Al}$ and $\mathrm{Sr}$ in $\mathrm{Si}$ after solidification.

The total amount of $\mathrm{Al}$ and $\mathrm{Sr}$ trapped in the Si-phase during solidification is also reported in Table III. The Al content of the unmodified plate-like Si-phase is nearly 4 times lower than the Al content in the modified coralline-like Si-phase. The total content of Sr in the Si-phase of the modified alloy is $860 \pm 560$ at-ppm. It should be noted here that the values reporting the total amount of $\mathrm{Al}$ and $\mathrm{Sr}$ in the Si phase present larger deviations than the solubility values because they strongly depend on the amount of segregations found in each tomography.

\section{Discussion}

\subsection{Unmodified alloy}

Doping and impurity atoms present in Si have been extensively investigated due to the importance of $\mathrm{Si}$ as a material for microelectronic applications. Carrier concentration profiles of heavily implanted $\mathrm{Al}$ in Si shows that only a small fraction of $\mathrm{Al}$ atoms contributes to the electrical activity in Si suggesting that part of the Al atoms are segregated or related to lattice defects [30]. This was supported by transmission electron microscopy showing dislocation loops and coherent precipitates 5 to $10 \mathrm{~nm}$ in size [30]. Such defects are also found in Si implanted by As, B or P [30-32]. Washburn et al [31] for example, shows a large number of small defects which could be dislocation loops or planar clusters of $\mathrm{P}$ atoms that are accompanied by lattice strain. Recently, Thompson et al [33] showed As-Cottrell atmospheres surrounding silicon interstitials and their evolution into decorated dislocation 
loops as a function of annealing. When interstitial and impurity atoms migrate into the proximity of a defect, the strain field around the defect will be relaxed, producing an energetically more favourable state. Similarly, Al segregations are formed in the Si eutectic phase of Al-Si alloys. The eutectic phase grows under an externally imposed cooling rate. Under such solidifying conditions, $\mathrm{Al}$ is incorporated in the Si lattice with a higher concentration than at thermodynamic equilibrium. Below the eutectic temperature, as the crystal is cooling down, there is a time period with high enough temperature to facilitate mobility and clustering of the excess Al. Preferential sites for these atoms are in the proximity of defects where the Si lattice is strained.

Nanometre sized defects in Si can be caused by the aggregation of Si interstitials into more complex defects $[33,34]$, or due to the entrapment of nanosized crystals forming pockets at the growth front. In the unmodified alloy, Si grows ahead of the solidifying front by the TPRE mechanism [24]. Given this anisotropic growth mode and due to the low solubility and low distribution coefficient of $\mathrm{Al}$ in $\mathrm{Si}(\mathrm{k}=0.002)$ [35], Al will be accumulated at the growth front. At a certain Al concentration, entrapment of this Al-rich layer in small pockets of high $\mathrm{Al}$ concentration can occur [34,36]. Moreover, Si clusters which were not completely dissolved in the melt can also be incorporated at the solidifying growth front resulting in interstitial lattice defects [37]. Such interstitials may aggregate and produce a strain field towards which Al will diffuse. As a consequence, the three types of Al segregations found by APT are impurity clouds surrounding defects in the Si lattice. Depending on the type of defect in the Si lattice and the time given for the Al segregation to evolve during cooling, different types of segregations are formed. They range from small Al clusters to larger clouds surrounding a Si-rich core, and finally to the decoration of even larger defects such as dislocation loops as seen in the ring-like segregation.

\subsection{Modified alloy}

The modification of the flaky eutectic structure in favour of a more fibrous or coralline one is thought to be a consequence of the competing growth of the Al and Si phases [4,5,7]. It is 
well documented that the unmodified plate-like Si structure grows in advance with respect to the Al phase $[2,3,7]$. When the flake-to-fibrous transition takes place this growth rate advantage is lost. As a result, both phases grow simultaneously at a common growth front, which changes the final microstructure.

One way to obtain such condition is to force the growth rate to exceed $400-500 \mu \mathrm{m} / \mathrm{s}$ by, for example, rapid cooling [5]. Thall and Chalmers [38] suggested that under such conditions the microstructural refinement is a consequence of the balance between heat flow from the liquid to the solid and heat evolved during solidification. The solid-liquid interface will advance more rapid when the thermal conductivity is high and the latent heat of fusion is low. For the present phases, the thermal conductivity of $\mathrm{Si}$ is lower than $\mathrm{Al}$, while the latent heat of fusion is higher. Because of these differences the growth rate will be similar or even faster for the Al phase.

An alternative way to produce a similar change in the growth front profile is by the addition of a minor element, e.g. Sr. This type of modification occurs at much lower solidification rates and, thus, it is more relevant for industrial processes. In this case, the phenomenon is explained by a reduction of the Si growth rate by mechanical obstruction and adsorption of the modifier into the Si crystal. This will produce a common growth front of the Al and $\mathrm{Si}$ eutectic phases $[2,10]$. The analysis of the nanometre sized features present in the Si phase is a key to understand how $\mathrm{Sr}$ is incorporated and how this translates into the microstructural modification.

\section{a. Rod-like segregations}

The modification of the Si-phase due to $\mathrm{Sr}$ addition is generally explained by a high multiplication of twins causing repeated changes in the crystallographic growth direction. Based on this interpretation, several twin boundaries and multiple crystallographic orientations would be expected in a transversal cut to the growth direction. The EBSD overview presented in figure 4(a), however, shows that most of the Si branches present only two different crystallographic orientations. This is corroborated in the TEM images (figure 
4(b,c); figure 9(a)) were also only two orientations are evident, even if the Si crystal presents a high density of defects.

Although changes of the overall growth direction due to twinning are seen in almost all branches, they are not as frequent as one would expect in order for twins to cause the entire change of morphology. In fact, over the years, the discrepancy between predicted and observed twin density has been given attention to elucidate if the presence of twins is really a determining factor for the modification. Shamsuzzoha and Hogan [8], for instance, showed that the twin density changed with cooling rate while a modified structure was observed for all studied cooling rates. Another example was presented by Nogita et al [39], who reported modification by $\mathrm{Ba}$ and $\mathrm{Ca}$, which produce a well modified structure with a lower amount of twins than expected.

In the present study, TEM and STEM images show that the most frequent features in the analysed sample are narrow defects embedded in the Si single crystal. These rod-like segregations involve only a few inter-planar distances and not necessarily an overall twinning of the crystal. This is supported by high-resolution images in figure $7(b, c)$ where no twin boundary is formed, and instead, only the stacking sequence of a few planes is changed. APT reveals an enrichment of $\mathrm{Al}$ and Sr pinning these features. To understand the influence of these rod-like defects on the modified structure we need to trace their origin and understand their composition.

Rod-like segregations have been observed in previous APT studies [18-20]. However, the three-dimensional complexity of the segregations was not captured until now when wider field of views were obtained. The reconstructed volume shown in figure 5 present rod-like segregations in several different crystallographic orientations. Such measurement also permitted spatial correlation between APT and TEM. It should be born in mind that these APT and TEM images originate from different samples prepared from the same alloy. Nevertheless, there is a 1:1 correlation in the thickness of each single segregation and the distances between them (figure 6) manifesting the high frequency of rod-like segregations in the structure. 
Numerous rod-like segregations found in both APT and TEM show a V-shaped morphology as the ones depicted in the overview and high-resolution images in figure 5, 6 and 7 . Socalled hairpin dislocations may form when an advancing solid-liquid interface encounters small nanometre sized crystalline clusters with a slightly different crystallographic orientation than the growing crystal. When such crystalline pockets are incorporated into the Si single crystal, their misorientation favour the formation of stacking faults or half loop dislocations [40-42]. Al-Si-Sr clusters were frequently found at the intersection of rod-like defects as shown in figure $7(\mathrm{a})$. Timpel et al $[18,19]$ reported similar defects showing segregations of $\mathrm{Al}$ and $\mathrm{Sr}$ at their intersections using energy dispersive x-ray spectroscopy, while atom-resolved STEM confirmed that the overall direction of the Si crystal was not changed.

The misoriented pockets and consequent formation of hairpin dislocations will interrupt the Si growth. The lattice planes emerging from such disturbance will be favourable sites for $\mathrm{Al}$ and Sr accumulated at the solid-liquid interface to be adsorbed and incorporated into the Si lattice. Once these elements are adsorbed, the defects are stabilized or pinned, not having the possibility to annihilate during the further cooling of the alloy. This proposed mechanism adheres to the well-accepted theories claiming adsorption of the modifier at the growth front $[2,10]$. However, we propose that these segregations restrict the Si growth and generate localized disturbances over a few inter-planar distances, instead of causing overall changes of the growth direction by repeated twinning as proposed by earlier theories.

The remaining item to address is related to the formation of the nanometre sized clusters that induce V-shape defects. Some insight to the nucleation of these clusters can be found in the build-up of a layer at the growth front during solidification. It is reasonable to assume that both $\mathrm{Al}$ and $\mathrm{Sr}$ are accumulated ahead of the growth front given their low solubility in Si. This is further supported by Kobayashi et al [43] who studied overmodified Al-Si samples by the addition of $\mathrm{Na}$ and reported the formation of an AI-Si-Na rich layer along the solidification interface. In the case of Sr-modification we propose a similar but subtler effect, with a thin AlSi-Sr layer forming at the growth front. This layer will act as a mechanical obstruction for the growth of the Si-phase and favour a nearly planar growth front. 
On this basis, local ternary phase reactions within this layer will assist in the nucleation of nanometre sized clusters responsible for V-shaped defects. Whether these clusters are crystalline or not, was not proven in the present study. However, based on our assumption that these clusters are a consequence of ternary phase reactions, we assume that they are crystalline. Such ternary reactions were studied, for example by Hanna and Hellawell [44] who determined the liquidus surface for the Al-Si-Sr phase diagram from 0-20 wt.\% Si and 05 wt.\% Sr. Their study presented a ternary reaction at $\mathrm{Al}-12.9$ at.\% Si - 0.6 at.\% Sr (Al 13.2 wt.\% Si -1.8 wt.\% Sr) around 2 to $3 \mathrm{~K}$ below the binary Al-Si eutectic. The Si concentration for this reaction to occur is near the binary eutectic point at 12.2 at.\% Si [45] and the $\mathrm{Sr}$ concentration of 0.6 at.\% can be easily reached at the growth front considering that all segregations measured by APT showed higher values (figures $5(d)$ and $8(b)$ ). Another evidence supporting local ternary reactions is the range of Al:Sr ratios found in the segregations. These ratios coincide with two known intermetallic phases related to this system: $\mathrm{Al}_{4} \mathrm{Sr}$ and $\mathrm{Al}_{2} \mathrm{Si}_{2} \mathrm{Sr}$. A recent investigation reports that $\mathrm{Sr}$ atoms segregate towards Si-rich regions and that the addition of trace levels of $\mathrm{Sr}$ results in the formation of $\mathrm{Al}_{2} \mathrm{Si}_{2} \mathrm{Sr}$ like clusters [46]. Formation of such clusters ahead of the solidification front and their incorporation in the Si-crystal to generate V-shaped defects would be consistent with the APT and TEM results. The reason why different elements have distinctive modifying efficiencies remains an open question. It is well known, for instance, that complete modification with $\mathrm{Na}$ can be achieved with lower $\mathrm{Na}$ concentration than with Sr. Different local ternary reactions for each element may be a factor determining these efficiencies. One of the most important structural changes responsible for the enhanced crack resistance of the Sr-modified alloy is that Si branches become more rounded and smoother in comparison to the elongated plates with sharp or angular edges of the unmodified alloy. Figure 9 presents two ways how rod-like segregations affect the structure at the microscopic level.

The first way is schematically shown in figure 9(b). It shows the direct influence of the rodlike segregations at the Al-Si phase boundary. Rod-like defects corresponding to Al-Sr 
segregations extend from the inner part of the branch until the Al-Si interface. During growth, the aggregation rate of $\mathrm{Si}$ is retarded at these defects by the adsorption of $\mathrm{Al}$ and $\mathrm{Sr}$. Consequently, the regions between the rod-like segregations at the phase boundary have a slightly higher growth rate and, therefore, the boundary seems to be pinned by the defects which are marked by the arrows in figure $9(\mathrm{~b})$. The net result of these types of features is a smoothening of the Al-Si phase boundary.

The second way the rod-like segregations appear to affect the modification is by influencing the twinned surface inside the Si branch. Almost all Si branches present one shift of the overall growth direction by a twin boundary (figure 4). Twin boundaries inside the Si phase were also seen for the unmodified sample. The difference between these alloys is that for the unmodified plate-like structure, the twin boundary is a unique plane which runs through the complete plate (figure 2), while in the Sr-modified sample the twinned boundary is irregular and changes directions repeatedly. This is schematically presented in figure 9 (c) and it is frequently observed in the TEM samples, e.g. in figure 4(c). The changes of the growth rate and the irregular growth front determined by the rod-like segregations will favour the accumulation of $\mathrm{Al}-\mathrm{Si}-\mathrm{Sr}$ layers in certain crystallographic directions over others. When the growth is completely obstructed by this layer, formation of a twin is favoured. This can be seen in figure 9 ( $a$ and $c$ ) where the irregular twin boundary follows the directions imposed by the V-shaped defects. Although the cause of the twin will be the segregation of $\mathrm{Al}$ and $\mathrm{Sr}$ at the front (see section 4.2.c), the irregularities of this boundary are a consequence of the growth front given by the rod-like segregations. The growth flexibility of the Si branches given by these boundaries favours a more isotropic growth of the Si branches.

\section{b. Particle-like segregations}

Two types of particles were distinguished in the Sr-modified sample: small precipitates under $10 \mathrm{~nm}$ in diameter, and larger ones over this size. In contrast to the unmodified Si-phase where all particles were homogeneously distributed, the Sr-modified Si phase presents regions with very high density of small precipitates $(<10 \mathrm{~nm})$ (figure $5(b))$. This high density of 
segregations shows how the Si-growth pushes $\mathrm{Al}$ and $\mathrm{Sr}$ ahead of the solidification front until a threshold level is reached and they are incorporated in the Si-phase. It is likely that the agglomeration of these segregations affects the advancement of the solidification front and contributes to the modification. In contrast, the larger particles have a similar density and distribution as in the unmodified alloy and they do not show any relevant correlation to the structural modification. Similarly as seen in the unmodified alloy, excess Al trapped in the Siphase diffuses to strained regions of the lattice forming impurity clouds.

\section{c. Planar segregations}

Planar segregations are considered to be a result of the progressive accumulation of $\mathrm{Al}$ and $\mathrm{Sr}$ at the solidifying interface. As it was explained in section 4.2.a, rod-like segregation will cause instabilities at the growing interface. These perturbations in the shape of the solidliquid interface of the Si faceted phase grow faster in certain crystallographic directions and become tangential to low-index faceting planes [34]. Al and Sr will be continuously rejected at these facets ending up in the formation of an enriched surface (planar segregation). Further growth of the Si crystal in this direction is hindered until this enriched layer is overgrowth and trapped in the Si lattice. Such planar segregations favour the formation of grain boundaries and irregular twin boundaries crossing through the entire Si branch as the one depicted in figure $9(\mathrm{c})$.

\subsection{Al and Sr concentrations in the Si phase}

The solubility of $\mathrm{Al}$ in $\mathrm{Si}$ is low and sometimes for practical reasons it is even considered to be zero. It is clear, however, that this practical assumption is not valid if the Si phase is analysed at a more detailed level. Data measured by diffusion [47] and temperature-gradient zone melting [48] showed solubilities lower than 0.035 at.\% at all temperatures. Trumbore [35] reviewed a number of conflicting studies showing discrepancies as high as three or four orders of magnitude in the solid solubility of Al in Si. In this study, Trumbore measured a solid solubility of 0.03 at. $\%$ at $720 \stackrel{\circ}{C}$ by spectrophotometric and spectroscopic analyses on 
crystals grown in thermal gradient experiments. In addition, he calculated the solidus curve by reinterpreting Gudmundsen and Maserjian's [49] low temperature curve by taking Backenstoss' mobility data [50] into account resulting in an Al solid-solubility near $6 \times 10^{18}$ at. $/ \mathrm{cm}^{3}\left(\sim 0.035\right.$ at.\%) at $600{ }^{\circ} \mathrm{C}$. These data agree with the values obtained by APT in this study. The amount of Al in solid solution in the Si phase is nearly the same in both alloys and ranges between $~ 300-600$ at-ppm.

The total amount of Al in the Si-phase is higher than the solubility limit for the unmodified and modified alloys (Table III). The total amount of Al in the unmodified alloy is $\sim 0.161$ at.\%, while in the modified is of $\sim 0.616$ at.\%. As both alloys were directionally solidified under the same temperature gradient and growth rate, the fourfold increase of Al content in the modified alloy as compared to the unmodified, can be explained by the presence of Sr. This finding supports the hypothesis that $\mathrm{Al}$ and $\mathrm{Sr}$ are incorporated together into the Si-phase in the form of nanometre sized phases as proposed in section 4.2.a.

The content of Sr in the Si-phase of the modified alloys was determined by APT. Just as for Al, the amount of $\mathrm{Sr}$ in solid solution ( $40 \pm 10$ at-ppm) is considerably lower than the total amount of Sr trapped in the Si-phase (860 \pm 560 at-ppm). This indicates that most of the Sr contained in the alloy is related to segregations. It is commonly accepted that Sr segregates to the Si phase of these alloys [12,51]. The total amount of Sr in the alloy is 46 at-ppm (150 wt-ppm) and if all this Sr was contained in the Si phase, the total Sr concentration in Si would be nearly 680 at-ppm. This concentration lies in the range measured by APT confirming that Sr predominantly segregates to the Si phase. This is vital information for the optimization of the alloy.

\section{Conclusion}

AISi7 alloys with and without Sr modification were analysed by APT, TEM and STEM. The composition and distribution of $\mathrm{Al}$ and $\mathrm{Sr}$ in the Si phase were studied and correlated to structural defects. 
The unmodified Si structure presented nanometre size Al segregations. The amount of Al trapped in Si during solidification is over its solubility limit, what makes Al to diffuse and decorate defects. These segregations do not influence the plate-like type of growth of the Si microstructure.

The coralline-like microstructure of the modified sample showed high density of defects enriched by Al-Sr segregations. Three distinctive features inherent to the structural modification were identified:

(a) Rod-like segregations which frequently showed a V-shape. These segregations influence the final round section and smoothening of the Si branches and the formation of irregular twin boundaries.

(b) Regions with high density of small particle-like segregations. These regions result from the accumulation of $\mathrm{Al}$ and $\mathrm{Sr}$ at the solidification front, what hinders the Si growth.

(c) Planar segregations at grain and twin boundaries.

Compositional analysis of the Si phase show solubilities of $430 \pm 160$ at-ppm Al and $40 \pm 10$ at-ppm Sr. The total amount of Al trapped in the Si phase is four times higher in the Sr modified alloy than in the unmodified, confirming that a large fraction of $\mathrm{Al}$ is incorporated together with Sr into the Si phase. Sr segregates predominantly to the Si phase confirming its importance in the modification of the eutectic growth.

The present study shows that high density of defects enriched by $\mathrm{Al}$ and $\mathrm{Sr}$ in the Si phase plays a decisive role in the modification of the Si microstructure. We propose that the nucleation of $\mathrm{Al}-\mathrm{Si}-\mathrm{Sr} / \mathrm{Al}-\mathrm{Sr}$ nanoclusters by local ternary reactions assists in the formation and pinning of defects.

Although changes in the Si crystallographic orientation by twinning is a relevant characteristic of this modification, different types of defects including stacking faults and hairpin dislocations should also be taken into account.

\section{Acknowledgments}


The present investigation is supported by funding from the German Federal Ministry of Economics and Technology (project: AiF 17204 N). The EU funding in the framework of the project AME-Lab (European Regional Development Fund C/4-EFRE-13/2009/Br) is gratefully acknowledged. The Atom Probe was financed by the DFG and the Federal State Government of Saarland (INST 256/298-1 FUGG). The authors thank V. Groten and Prof. Dr.-Ing. A. Bührig-Polaczek (Foundry Institute at RWTH Aachen) for providing the samples, Dr. H. Schmidt for helping with STEM, and Prof. Dr. E. Arzt for continuous support through INM. J. Barrirero acknowledges the Erasmus Mundus Programme of the European Commission within the Doctoral Programme DocMASE for financial support. N. Ghafoor acknowledges VINNOVA Strategic Faculty Grant VINNMER - Marie Curie Chair for financial support.

\section{References}

[1] J.E. Gruzleski, B. Closset, The treatment of liquid Aluminum-Silicon alloys, American Foundrymens Society, 1990.

[2] M.G. Day, A. Hellawell, The Microstructure and Crystallography of Aluminium-Silicon Eutectic Alloys, Proc. R. Soc. A Math. Phys. Eng. Sci. 305 (1968) 473-491.

[3] A. Hellawell, The growth and structure of eutectics with silicon and germanium, Prog. Mater. Sci. 15 (1970) 3-78.

[4] H.A.. Steent, A. Hellawell, Structure and properties of aluminium-silicon eutectic alloys, Acta Metall. 20 (1972) 363-370.

[5] D.C. Jenkinson, L.M. Hogan, The modification of aluminium-silicon alloys with strontium, J. Cryst. Growth. 28 (1975) 171-187.

[6] M.D. Hanna, S.-Z. Lu, A. Hellawell, Modification in the aluminum silicon system, Metall. Trans. A. 15 (1984) 459-469.

[7] K.F. Kobayashi, L.M. Hogan, The crystal growth of silicon in Al-Si alloys, J. Mater. Sci. 20 (1985) 1961-1975.

[8] M. Shamsuzzoha, L.M. Hogan, The crystal morphology of fibrous silicon in strontiummodified Al-Si eutectic, Philos. Mag. A. 54 (1986) 459-477.

[9] M. Shamsuzzoha, L.M. Hogan, Crystal morphology of unmodified aluminium-silicon eutectic microstructures, J. Cryst. Growth. 76 (1986) 429-439. 
[10] S. Lu, A. Hellawell, The mechanism of silicon modification in aluminum-silicon alloys: Impurity induced twinning, Metall. Trans. A. 18 (1987) 1721-1733.

[11] M. Shamsuzzoha, L.M. Hogan, The twinned growth of silicon in chill-modified Al-Si eutectic, J. Cryst. Growth. 82 (1987) 598-610.

[12] L. Clapham, R.W. Smith, Segregation behaviour of strontium in modified and unmodified Al-Si alloys, J. Cryst. Growth. 92 (1988) 263-270.

[13] S.D. McDonald, K. Nogita, A.K. Dahle, Eutectic nucleation in Al-Si alloys, Acta Mater. 52 (2004) 4273-4280.

[14] A.K. Dahle, K. Nogita, S.D. McDonald, J.W. Zindel, L.M. Hogan, Eutectic nucleation and growth in hypoeutectic Al-Si alloys at different strontium levels, Metall. Mater. Trans. A. 32 (2001) 949-960.

[15] A.K. Dahle, K. Nogita, S.D. McDonald, C. Dinnis, L. Lu, Eutectic modification and microstructure development in Al-Si Alloys, Mater. Sci. Eng. A. 413-414 (2005) 243248.

[16] S.D. McDonald, A.K. Dahle, J.A. Taylor, D.H. StJohn, Eutectic grains in unmodified and strontium-modified hypoeutectic aluminum-silicon alloys, Metall. Mater. Trans. A. 35 (2004) 1829-1837.

[17] M.E. van Dalen, R.A. Karnesky, J.R. Cabotaje, D.C. Dunand, D.N. Seidman, Erbium and ytterbium solubilities and diffusivities in aluminum as determined by nanoscale characterization of precipitates, Acta Mater. 57 (2009) 4081-4089.

[18] M. Timpel, N. Wanderka, R. Schlesiger, T. Yamamoto, N. Lazarev, D. Isheim, et al., The role of strontium in modifying aluminium-silicon alloys, Acta Mater. 60 (2012) 3920-3928.

[19] M. Timpel, N. Wanderka, R. Schlesiger, T. Yamamoto, D. Isheim, G. Schmitz, et al., $\mathrm{Sr}-\mathrm{Al}-\mathrm{Si}$ co-segregated regions in eutectic Si phase of Sr-modified Al-10Si alloy., Ultramicroscopy. 132 (2013) 216-21.

[20] J. Barrirero, M. Engstler, F. Mücklich, Atom Probe analysis of Sr distribution in AISi foundry alloys, in: Light Met. 2013 - TMS, 2013: pp. 291-296.

[21] K. Thompson, D. Lawrence, D.J. Larson, J.D. Olson, T.F. Kelly, B. Gorman, In situ site-specific specimen preparation for atom probe tomography., Ultramicroscopy. 107 (2007) 131-9.

[22] J. Schindelin, I. Arganda-Carreras, E. Frise, V. Kaynig, M. Longair, T. Pietzsch, et al., Fiji: an open-source platform for biological-image analysis., Nat. Methods. 9 (2012) 676-82.

[23] F. Lasagni, A. Lasagni, C. Holzapfel, F. Mücklich, H.P. Degischer, Three Dimensional Characterization of Unmodified and Sr-Modified Al-Si Eutectics by FIB and FIB EDX Tomography, Adv. Eng. Mater. 8 (2006) 719-723.

[24] D.R. Hamilton, R.G. Seidensticker, Propagation Mechanism of Germanium Dendrites, J. Appl. Phys. 31 (1960) 1165. 
[25] C.M. Eichfeld, S.S. a Gerstl, T. Prosa, Y. Ke, J.M. Redwing, S.E. Mohney, Local electrode atom probe analysis of silicon nanowires grown with an aluminum catalyst., Nanotechnology. 23 (2012) 215205.

[26] B. Gault, M.P. Moody, J.M. Cairney, S.P. Ringer, Atom Probe Microscopy, Springer New York, New York, NY, 2012.

[27] C. Oberdorfer, G. Schmitz, On the field evaporation behavior of dielectric materials in three-dimensional atom probe: a numeric simulation., Microsc. Microanal. 17 (2011) 15-25.

[28] W. Lefebvre, F. Danoix, G. Da Costa, F. De Geuser, H. Hallem, A. Deschamps, et al., 3DAP measurements of Al content in different types of precipitates in aluminium alloys, Surf. Interface Anal. 39 (2007) 206-212.

[29] T.F. Kelly, M.K. Miller, Invited review article: Atom probe tomography., Rev. Sci. Instrum. 78 (2007) 031101.

[30] D.K. Sadana, M.H. Norcott, R.G. Wilson, U. Dahmen, Transmission electron microscopy of aluminum implanted and annealed (100) Si: Direct evidence of aluminum precipitate formation, Appl. Phys. Lett. 49 (1986) 1169.

[31] J. Washburn, G. Thomas, H.J. Queisser, Diffusion-Induced Dislocations in Silicon, J. Appl. Phys. 35 (1964) 1909.

[32] C. Carter, W. Maszara, D.K. Sadana, G. a. Rozgonyi, J. Liu, J. Wortman, Residual defects following rapid thermal annealing of shallow boron and boron fluoride implants into preamorphized silicon, Appl. Phys. Lett. 44 (1984) 459.

[33] K. Thompson, P.L. Flaitz, P. Ronsheim, D.J. Larson, T.F. Kelly, Imaging of arsenic Cottrell atmospheres around silicon defects by three-dimensional atom probe tomography., Science. 317 (2007) 1370-4.

[34] D.T.J. Hurle, Crystal Pulling from the melt, Springer Berlin Heidelberg, 1993.

[35] F.A. Trumbore, Solid Solubilities of Impurity Elements in Germanium and Silicon*, Bell Syst. Tech. J. 39 (1960) 205-233.

[36] G.A. Chadwick, Eutectic alloy solidification, Prog. Mater. Sci. 12 (1963) 99-182.

[37] J. Zhang, H. Yu, S.B. Kang, J.H. Cho, G. Min, Modification of horizontal continuous casting Al-12\%Si alloy using FSM master alloy, Mater. Charact. 75 (2013) 44-50.

[38] B.M. Thall, B. Chalmers, Modification in Aluminum-Silicon Alloys, J. Inst. Met. 77 (1950) 79-97.

[39] K. Nogita, J. Drennan, A.K. Dahle, Evaluation of Silicon Twinning in Hypo-Eutectic AlSi Alloys, Mater. Trans. 44 (2003) 625-628.

[40] L.D. Glowinski, K.N. Tu, P.S. Ho, Direct observations of defects in implanted and postannealed silicon wafers, Appl. Phys. Lett. 28 (1976) 312.

[41] T. Sands, J. Washburn, E. Myers, D.K. Sadana, On the origins of structural defects in BF2+-implanted and rapid-thermally-annealed silicon: Conditions for defect-free 
regrowth, Nucl. Instruments Methods Phys. Res. Sect. B Beam Interact. with Mater. Atoms. 7-8 (1985) 337-341.

[42] K.S. Jones, S. Prussin, E.R. Weber, A systematic analysis of defects in ion-implanted silicon, Appl. Phys. A Solids Surfaces. 45 (1988) 1-34.

[43] K. Kobayashi, P. Shingu, R. Ozaki, Banded Structure in Aluminium-Silicon Eutectic Alloy, Trans. Japan Inst. Met. 21 (1980) 417-424.

[44] M.D. Hanna, A. Hellawell, Modificatio of Al-Si microstructure - the Al-Si-Sr phase diagram from 0-20 wt.\% Si and 0-5.0 wt.\% Sr, in: L.H. Bennett, T.B. Massalski, B.C. Giessen (Eds.), Alloy Phase Diagrams, Elsevier science publishing, New York, 1983: pp. 411-416.

[45] J.L. Murray, A.J. McAlister, The Al-Si (Aluminum-Silicon) system, Bull. Alloy Phase Diagrams. 5 (1984) 74-84.

[46] P. Srirangam, S. Chattopadhyay, A. Bhattacharya, S. Nag, J. Kaduk, S. Shankar, et al., Probing the local atomic structure of Sr-modified Al-Si alloys, Acta Mater. 65 (2014) 185-193.

[47] R.C. Miller, A. Savage, Diffusion of Aluminum in Single Crystal Silicon, J. Appl. Phys. 27 (1956) 1430.

[48] D. Navon, V. Chernyshov, Retrograde Solubility of Aluminum in Silicon, J. Appl. Phys. 28 (1957) 823.

[49] R.A. Gudmundsen, J. Maserjian, Semiconductor Properties of Recrystallized Silicon in Aluminum Alloy Junction Diodes, J. Appl. Phys. 28 (1957) 1308.

[50] G. Backenstoss, Conductivity Mobilities of Electrons and Holes in Heavily Doped Silicon, Phys. Rev. 108 (1957) 1416-1419.

[51] K. Nogita, H. Yasuda, K. Yoshida, K. Uesugi, a. Takeuchi, Y. Suzuki, et al., Determination of strontium segregation in modified hypoeutectic Al-Si alloy by micro X-ray fluorescence analysis, Scr. Mater. 55 (2006) 787-790.

Tables

Table I: Chemical composition measured by optical emission spectroscopy (wt.\%)

\begin{tabular}{ccccccc}
\hline & Si & Sr & Ti & Ca & Na & $\begin{array}{c}\text { Fe, Cu, Mn, Mg, Cr, } \\
\mathbf{N i}, \mathbf{Z n}, \mathbf{B i}, \mathbf{P}, \mathbf{P b}, \mathbf{S b}, \\
\text { V }\end{array}$ \\
\hline AlSi7 & 7.04 & - & 0.0006 & 0.0002 & $<0.0001$ & $<0.001$ \\
AlSi7 + 150 wt-ppm Sr & 7.04 & 0.015 & 0.0006 & 0.0002 & $<0.0001$ & $<0.001$ \\
\hline
\end{tabular}


Table II: Summary of segregations found in the unmodified and Sr-modified AISi7 alloy.

\begin{tabular}{cccc}
\hline Segregations & AlSi7 - (unmodified) & AlSi7 + 150ppm Sr (modified) \\
\hline Particle-like & small precipitates & $<10 \mathrm{~nm}-\mathrm{Al}$ (fig.3(b)) & $<10 \mathrm{~nm}-\mathrm{Al}, \mathrm{Sr}$ (fig.5(b)) \\
\cline { 2 - 4 } & larger precipitates & $>10 \mathrm{~nm}-\mathrm{Al}$ (fig.3(c)) & $>10 \mathrm{~nm}-\mathrm{Al}, \mathrm{Sr}$ (fig. 8(c)) \\
\hline Ring-like & $40 \mathrm{~nm}-\mathrm{Al}$ (fig.3(d)) & - \\
\hline Rod-like & - & $3 \mathrm{~nm}-\mathrm{Al}: \mathrm{Sr}=2.5 / 4.0$ (fig.5-7) \\
\hline Planar & - & $1-3 \mathrm{~nm}-\mathrm{Al}: \mathrm{Sr}=2.5 / 4.0$ (fig.8) \\
\hline
\end{tabular}

Table III: Minor elements' content in the eutectic Si phase (at.\%)

\begin{tabular}{ccccc}
\hline & $\begin{array}{c}\text { Al in the } \\
\text { specimens }\end{array}$ & $\begin{array}{c}\text { Al dissolved } \\
\text { in the } \mathrm{Si} \\
\text { matrix }\end{array}$ & $\begin{array}{c}\text { Sr in the } \\
\text { specimens }\end{array}$ & $\begin{array}{c}\text { Sr dissolved in } \\
\text { the Si matrix }\end{array}$ \\
\hline AlSi7 & $0.161 \pm 0.109$ & $0.036 \pm 0.009$ & - & - \\
AlSi7 + 150 wt-ppm Sr & $0.616 \pm 0.233$ & $0.047 \pm 0.012$ & $0.086 \pm 0.056$ & $0.004 \pm 0.001$ \\
\hline
\end{tabular}

\section{Figures}

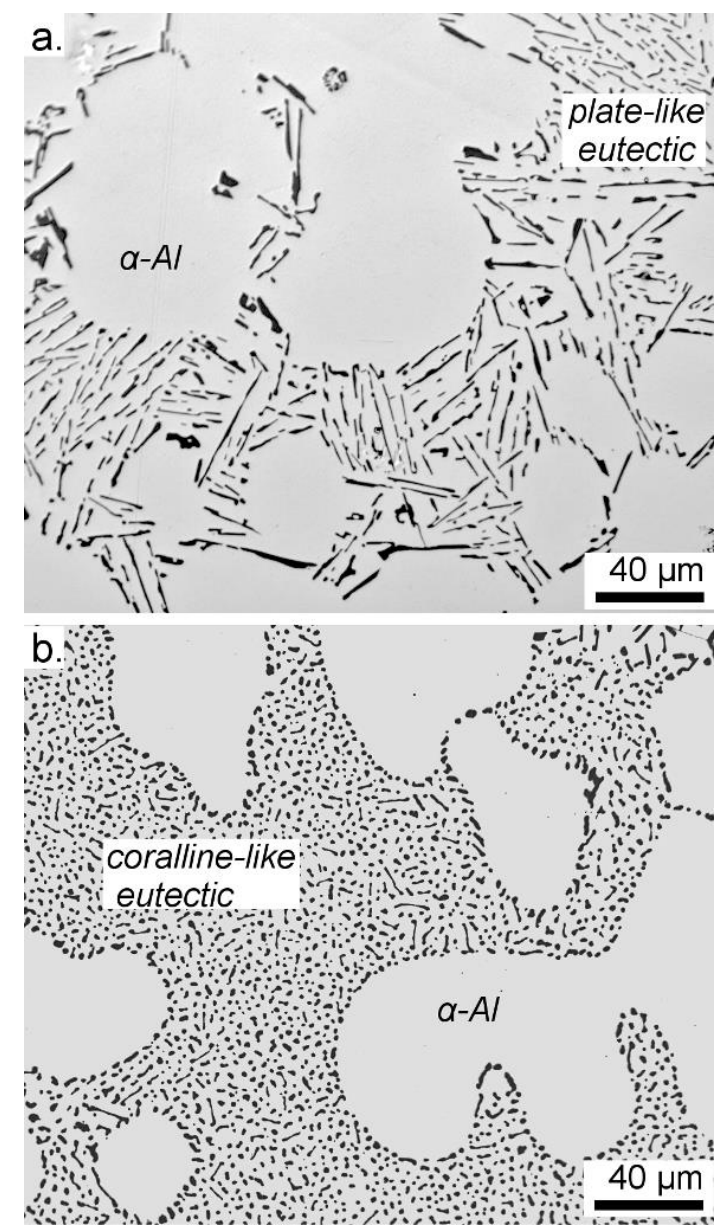


Figure 1: Optical micrographs of the analysed samples; (a) unmodified AISi7 alloy showing plate-like Si eutectic structure, (b) modified AISi7 + 150ppmSr with coralline-like Si structure (adapted from Barrirero et al[20]).
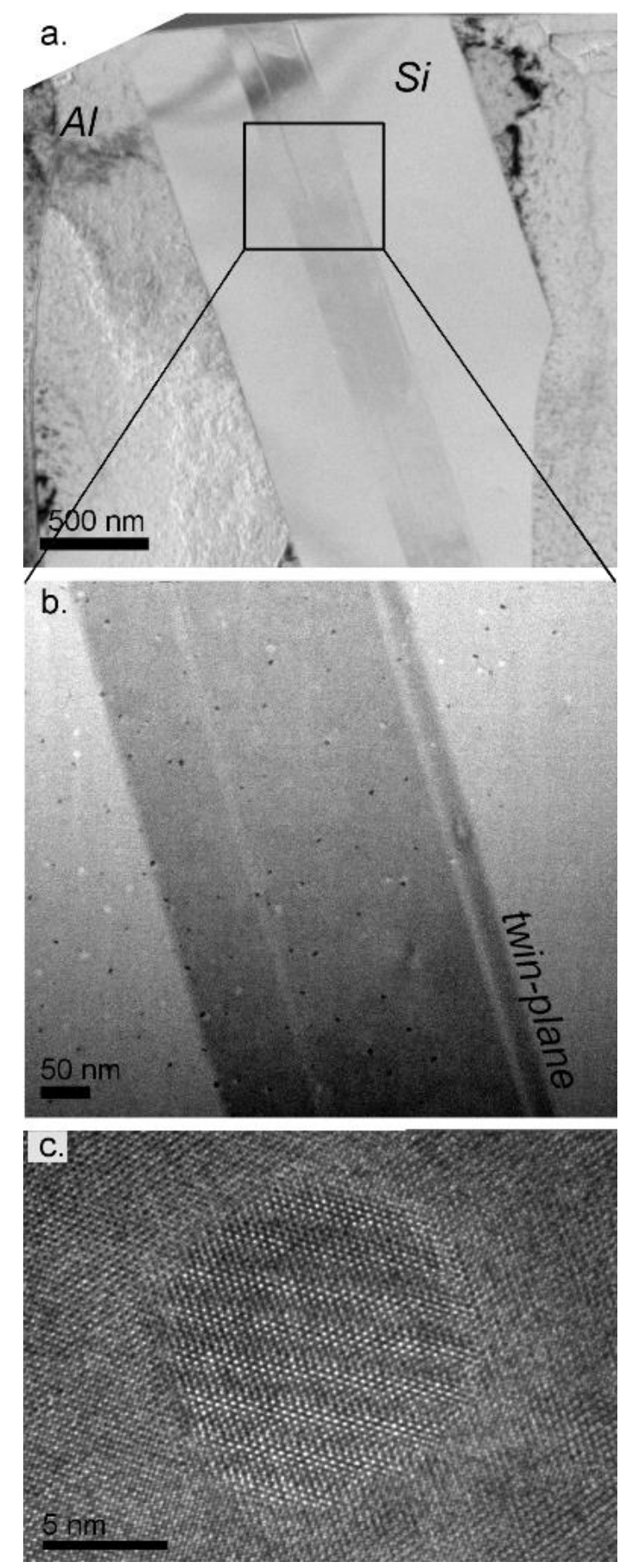

Figure 2: Transmission electron microscopy (TEM) images of the unmodified eutectic phase; (a) transversal cut of a Si plate, (b) zoom in of the centre of the plate showing twin planes of 
the twin plane re-entrant edge (TPRE) type of growth and small precipitates, (c) HR-TEM of one precipitate.
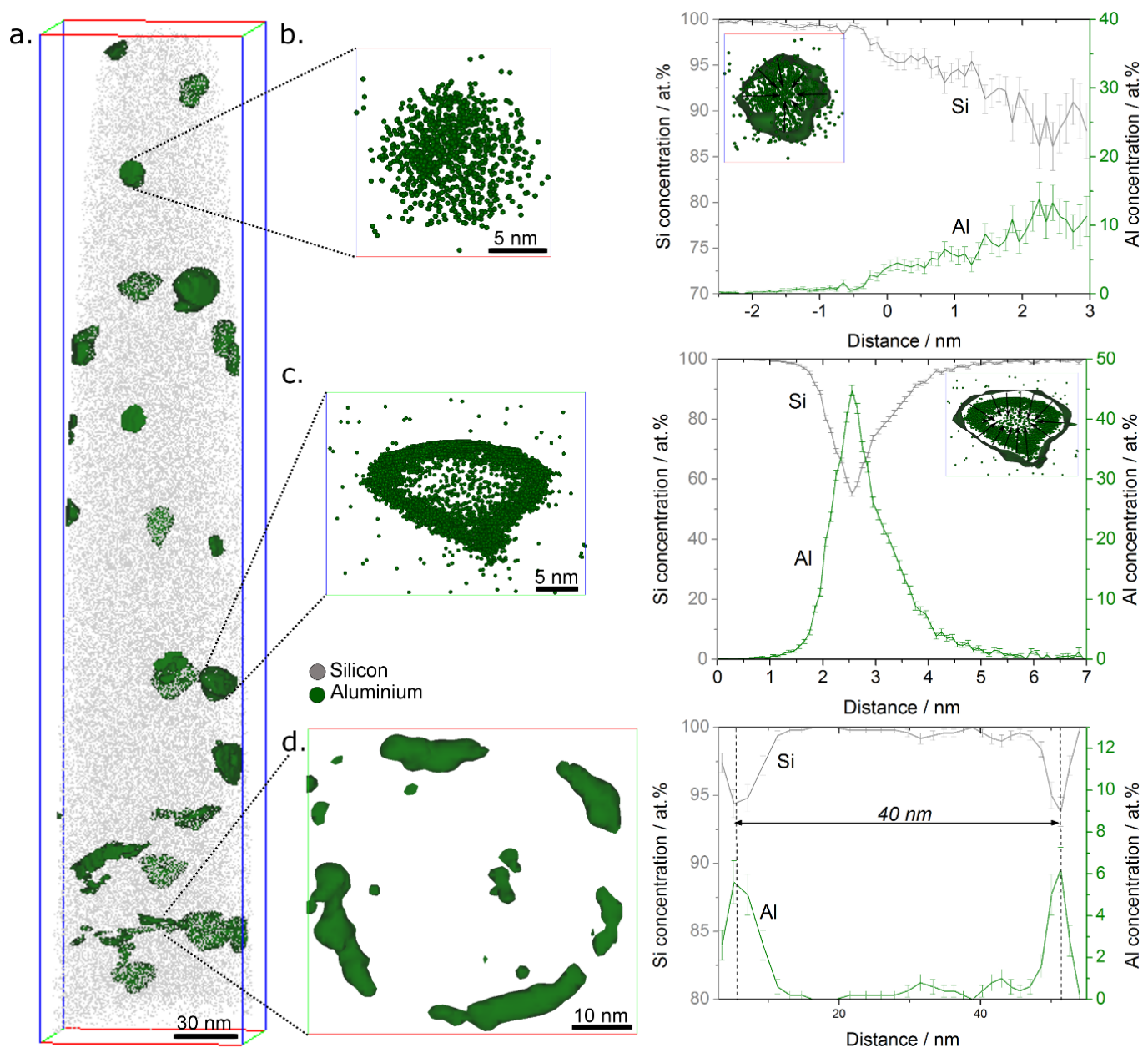

Figure 3: Atom probe tomography (APT) of the unmodified eutectic Si with the three distinctive types of segregations; (a) complete measurement with Al segregations depicted by 2 at.\% Al iso-concentration surface, (b) small Al segregation, proximity histogram showing the concentration profile as a function of the distance to an Al iso-concentration surface (2.5 at.\% Al) (black arrows in the diagram depict the positive increment of the $\mathrm{x}$-axis [distance]),(c) larger Al segregation showing an Al-depleted zone in the centre, proximity histogram showing the concentration profile as a function of the distance to an $\mathrm{Al}$ isoconcentration surface $(0.5$ at.\% $\mathrm{Al})$, (d) ring-like segregation [top view] with one-dimensional concentration profile. 


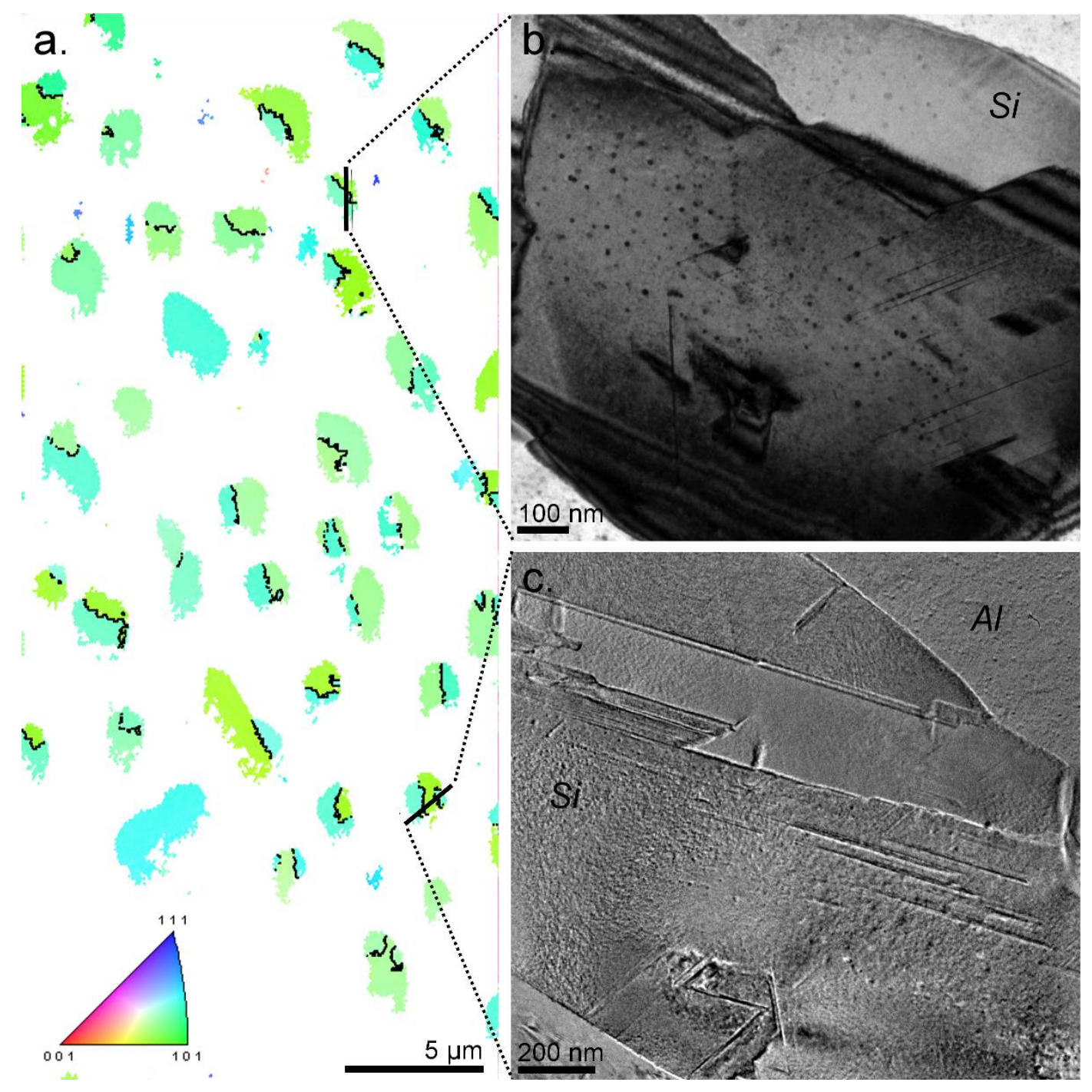

Figure 4: Overview of the modified eutectic phase (AISi7 + $150 \mathrm{ppm} \mathrm{Sr);} \mathrm{(a)} \mathrm{inverse} \mathrm{pole}$ figure map (electron backscattered diffraction - EBSD) perpendicular to the sample's growth direction. The map shows the crystallographic orientations of the silicon phase. Twin boundaries are shown in black. White areas correspond to the Al matrix which was filtered out for clarity, (b) diffraction contrast bright-field and (c) bright-field TEM overview images of Si modified branches. Each image shows two different crystallographic orientations in Si in agreement with the EBSD data. Nanometric rod-like and particle-like defects can be seen. 

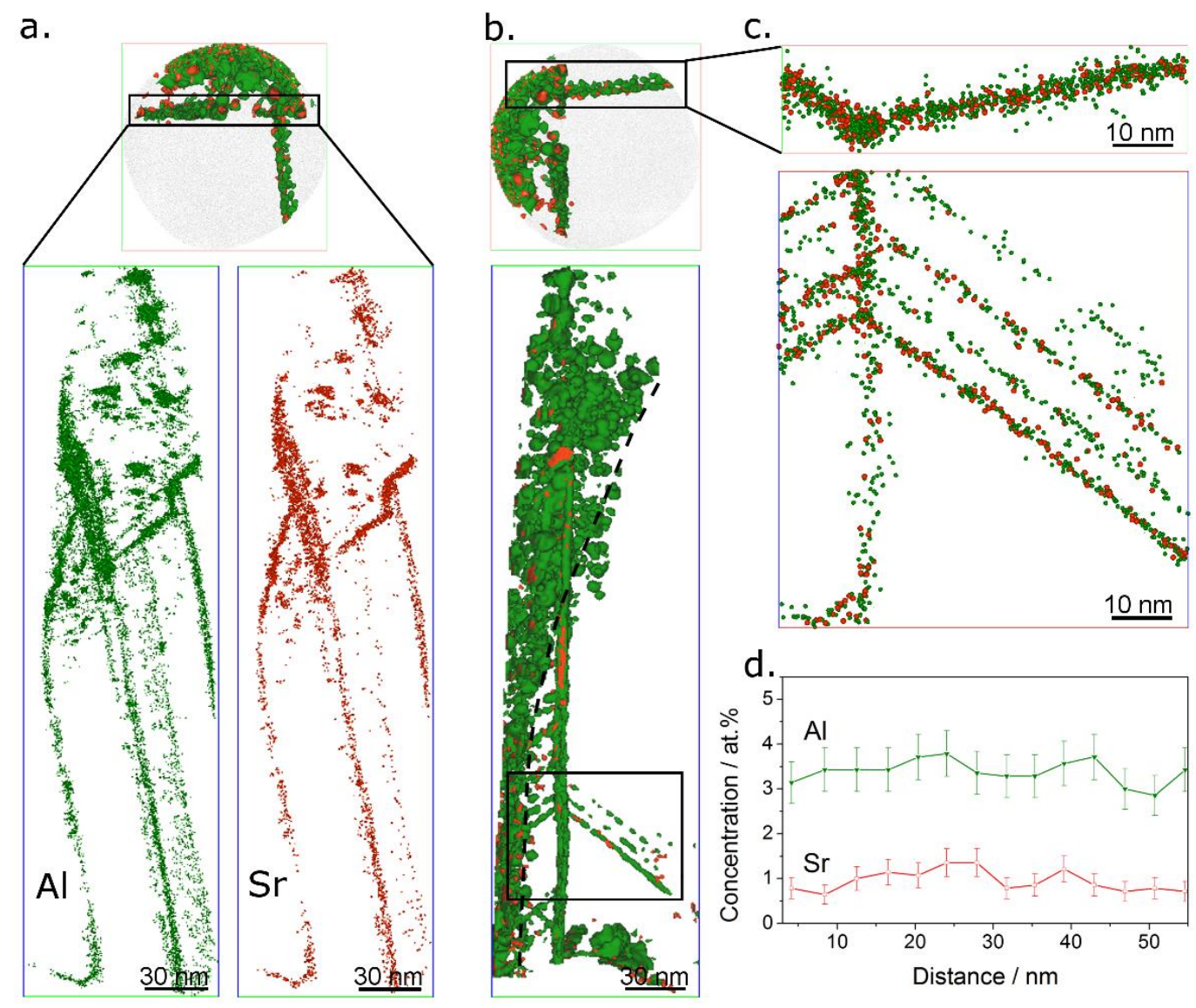

Figure 5: APT of the modified Si eutectic phase; (a) Top- and lateral-view of an $8 \mathrm{~nm}$ slice in the APT measurement. Rod-like segregations rich in $\mathrm{Al}$ and $\mathrm{Sr}$ are shown, (b) $90^{\circ}$ rotation of the same specimen showing particle-like segregations and further rod-like segregations (isoconcentration surfaces at 0.5 at.\% Sr and 0.6 at.\% Al), (c) magnified region of interest depicting the three-dimensional relations and complexity of the structure ( $\mathrm{Al}$ and $\mathrm{Sr}$ atoms are represented by spheres), (d) concentration profile along one single rod-like segregation showing an Al:Sr ratio of about 3. 


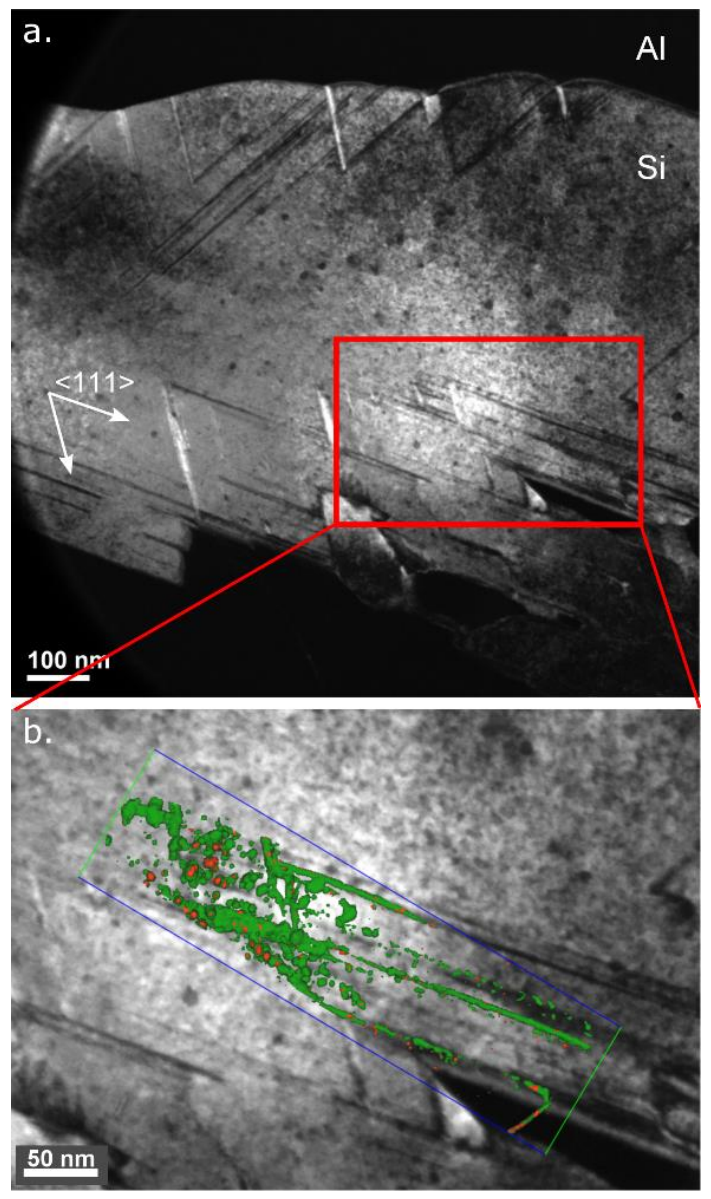

Figure 6: TEM-APT correlation; (a) dark-field TEM overview of a Si branch with numerous Vshaped defects along two $<111>$ directions, (b) magnified area of (a) and superimposed correlation with the segregations presented in APT in figure 5(a). 

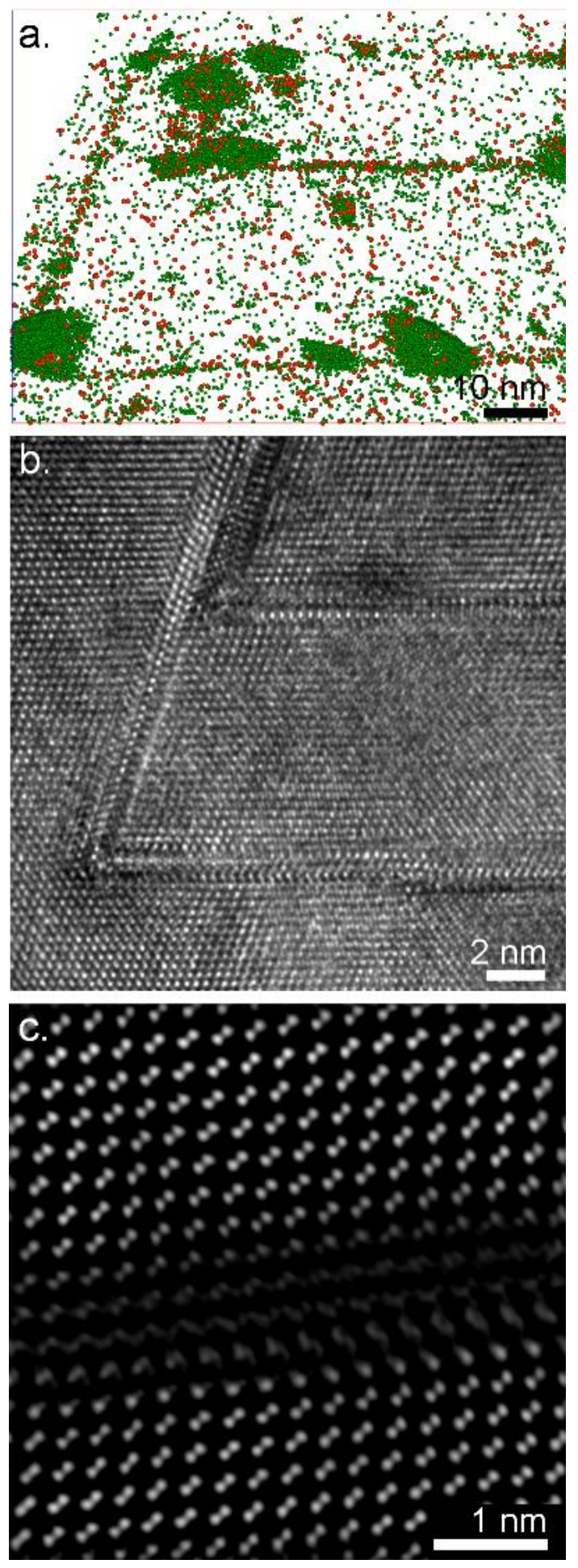

Figure 7: High resolution images of the rod-like defects in the Si phase; (a) rod-like and particle-like segregations containing $\mathrm{Al}$ (green) and $\mathrm{Sr}$ (red) atoms. Si atoms are not shown for clarity, (b) HR-TEM of two V-shape defects along $\{111\}$ planes, (c) HR-STEM showing a 1 nm-thick defect involving 3 lattice planes and no change of orientation at both sides of the defect. 

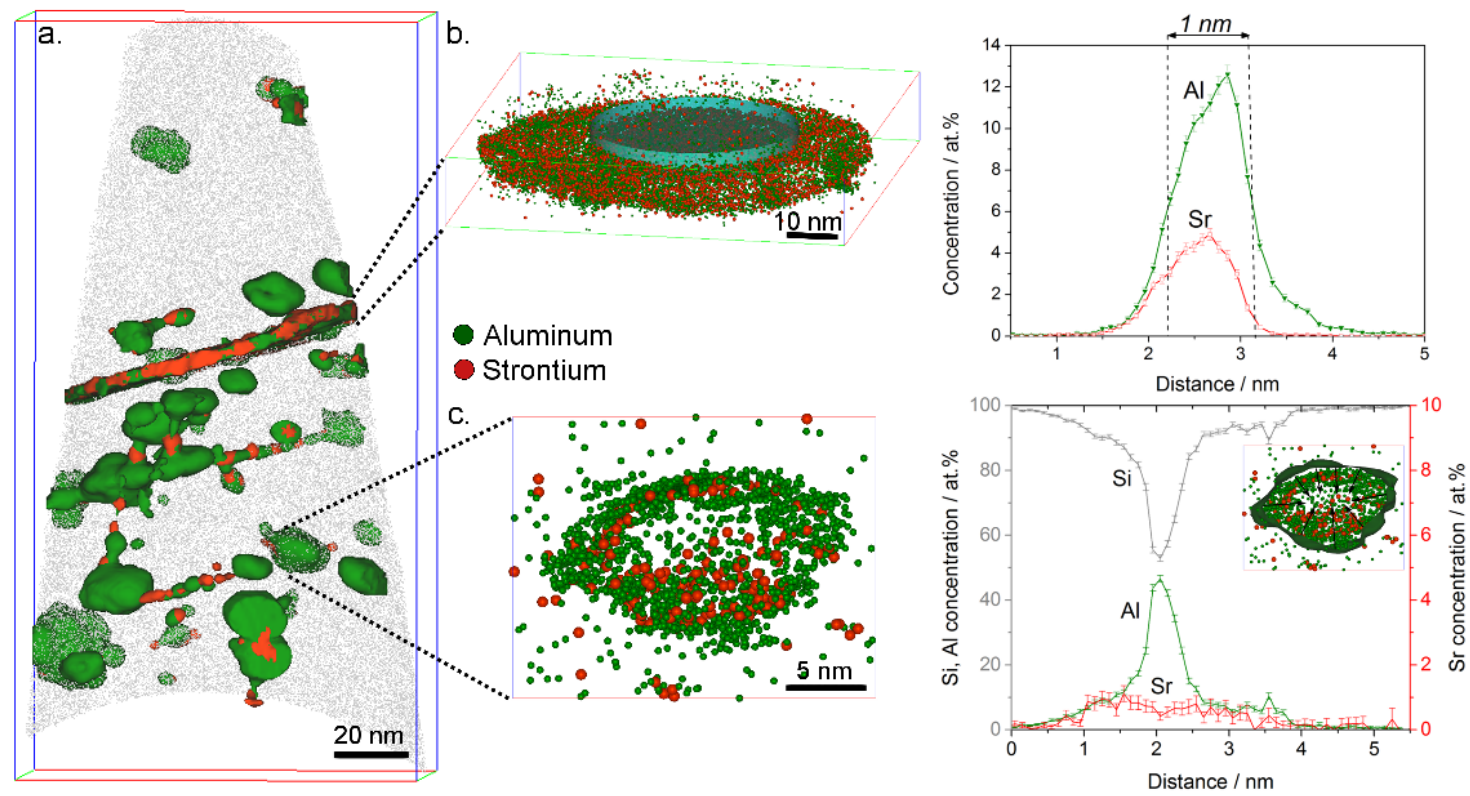

Figure 8: APT of the modified eutectic Si phase; (a) complete reconstruction highlighting AlSr segregations by iso-concentration surfaces (1.2 at.\% Al; 0.4 at.\% Sr). All three types of segregations are present, i.e. rod-like, particle-like and planar, (b) magnified planar segregation with a cylindrical region of interest - $\mathrm{ROI}$ ( $40 \mathrm{~nm}$ in diameter) used to measure the concentration profile, (c) slice of a particle-like segregation depicting an $\mathrm{Al}$ and $\mathrm{Sr}$ depleted region in the centre, proximity histogram showing $\mathrm{Si}, \mathrm{Al}$ and $\mathrm{Sr}$ concentration profiles as a function of the distance to an $\mathrm{Al}$ iso-concentration surface ( $2.5 \mathrm{at} \% \mathrm{Al})$ (black arrows in the diagram depict the positive increment of the x-axis [distance]).

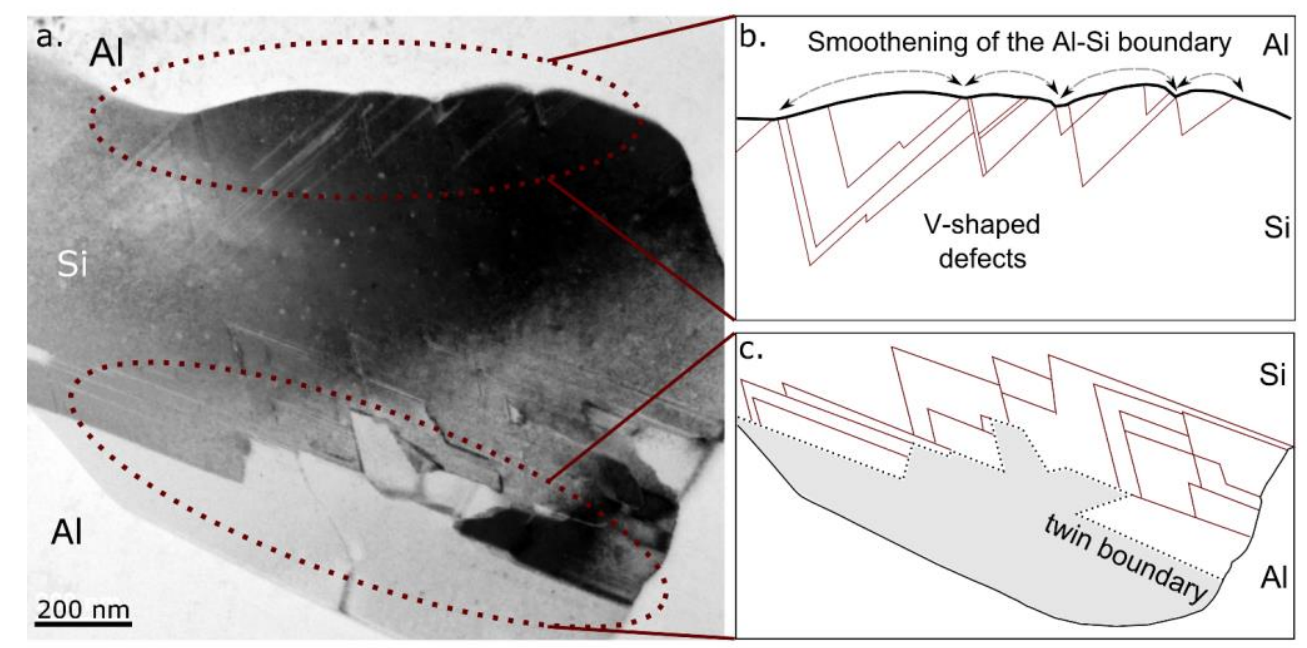


Figure 9: Influence of the V-shaped defects on the Si growth; (a) TEM overview of a modified Si branch, (b) illustration of the smoothening of the Al-Si boundary by the presence of V-shaped defects, (c) formation of an irregular twin boundary following the growth front determined by $\mathrm{V}$-shaped defects.

\section{Supplementary content - Captions}

Video 1: Rod-like and particle-like segregations in the modified eutectic Si phase. Atom probe tomography (APT) showing Si (gray), Al (green) and Sr (red) atoms; and isoconcentration surfaces at 0.6 at.\% $\mathrm{Al}$ and 0.2 at.\% Sr.

Video 2: Planar, particle-like and rod-like segregations in the modified eutectic Si phase. Atom probe tomography (APT) showing Si (gray), Al (green) and Sr (red) atoms; and isoconcentration surfaces at 1.5 at.\% $\mathrm{Al}$ and 0.3 at.\% $\mathrm{Sr}$. 